\title{
Acquisition of phonology in child Icelandic Sign Language: Unique findings
}

\author{
Elena Koulidobrova \& Nedelina Ivanova*
}

\begin{abstract}
Research shows that acquisition of sign language phonology is a developmental process and involves multiple articulatory cues. Among these cues, handshape has been shown to be crucial and orientation has been argued to be potentially disregardable as being internal to sign production rather than encoding a minimal contrast. We administered a non-word repetition task and a picture naming task to 17 (age 3-15) deaf and hard-of-hearing signers of Icelandic Sign Language (ÍTM) — an endangered indigenous language of the Deaf community in Iceland - targeting the same articulatory features. The tasks were modeled after similar assessment tools for other languages. All of the participants use ÍTM for daily activities at school and at home; the vast majority were early learners (before $36 \mathrm{~ms}$ ). Results show an upward trajectory in the non-word repetition task scores but without a ceiling effect. Contrary to predictions, no effect of handshape was observed. Instead, on both pseudo- and real-word tasks, the majority of errors were in orientation/mirroring. The results suggest that orientation plays a non-trivial role in acquisition of sign language phonology.
\end{abstract}

Keywords. sign language; acquisition; phonology; child language; bilingualism; endangered language

1. Introduction. Linguistic development of deaf and hard of hearing (DHH) children is a complicated matter. For example, it is well known that the vast majority of DHH children do not grow up in signing households: 95\% are born to hearing families (Karchmer \& Mitchell 2003, a.o.). What this means that in most countries, most deaf children are not exposed to a sign language early, or at least early enough for typical language acquisition process to be observable; instead, they are language deprived (Krausneker 2013, Reagan 2019, Skutnabb-Kangas \& Danbar 2010, DeMeulder et al. 2019, i.a.). This, in turn, suggests, that analysis of DHH children's linguistic development must be done bidirectionally, since the norm/typicality/standard remains an elusive goal (Mayberry 2007, Mann \& Haug 2014, et seq.). The research community has thus employed a variety of assessment techniques to address this issue directly. One way of establishing of what it means to be a typically developing DHH user of a sign language is to use tools that have been found to correlate with overall linguistic development in spoken languages. One such tool is a non-word repetition task, which probes the ability of a DHH signing child to replicate possible, but non-existent, 'signs,' thus assessing whether she has figured out phonological requirements of the language she is acquiring. It turns out, just like the hearing children (Dollaghan \& Campbell 1998; Gallon, Harris, \& van der Lely 2007; Gathercole

\footnotetext{
* We would like to thank our participants and assistants: children and their families, Deaf Association of Iceland, students, faculty and staff at the Solborg and Hlíðaskóli in Reykjavik, staff at the Communication Center for the Deaf and Hard of Hearing, Reykjavik, and interpreters. We are especially grateful to Svava Jóhannesdóttir and Júlía G. Hreinsdóttir. This project is supported by: University of Iceland, a grant from the Development Fund for Immigrant Affairs 2019 to the Communication Centre for the Deaf and Hard of Hearing, Iceland, and CSU AAUP Grants ARKOUJ and ARKOUK to E. Koulidobrova. The content is the sole responsibility of the researchers and does not represent official views of the granting agencies. Authors: Elena Koulidobrova, Central Connecticut State University (elena.koulidobrova@ccsu.edu) \& Nedelina Ivanova, Communication Center for the Deaf and Hard of Hearing, Iceland (nedelinas@ shh.is).
} 
\& Baddeley 1990, i.a.), in DHH children, success on such a task predicts success on other language measures (Mann Marshall 2010, Enns \& Herman 2011, Allen \& Enns 2013, i.a.). In this paper, we follow suit. However, we also note that the profile of DHH children participating in the studies reported here is somewhat different from the typical profile associated with DHH children (as articulated above). This is because the children whose linguistic development is being examined here are born and raised in Iceland.

2. Iceland: A unique setting. Iceland is a small Northern European country located in the middle of the Atlantic Ocean, with a population of $\sim 337,780$. According to World Atlas (worldatlas.com), 93.2\% of Icelanders speak Icelandic; the second largest linguistic community is Polish speakers (2.7\%). All other languages are used by fewer than $1 \%$ of all Icelanders. In the country, two languages are indigenous: Icelandic and Icelandic Sign Language (íslensk táknmál, or ÍTM).

ITM is also the only endangered language in the country. According to the Icelandic Parliament, ÍTM is to be considered a 'first language' for the DHH community and their family members (deaf or hearing); see (1). Iceland has also committed to support development and documentation of ÍTM, independently of its relation (or lack thereof) to deafness (see Stefansdóttir et al. 2019 and Koulidobrova et al. 2020 for discussion).

(1) Article 3. Icelandic sign language:

Icelandic sign language is the first language of those who have to rely on it for expression and communication, and of their children. The government authorities shall nurture and support it. All those who need to use sign language shall have the opportunity to learn and use Icelandic sign language as soon as their language acquisition process begins, or from the time when deafness, hearing impairment or deaf-blindness is diagnosed. Their immediate family members shall have the same right.

(Althing Act no. 61/2011, Article 3)

ÍTM is historically related to Danish Sign Language (SL); relatedly, until 1910, all DHH individuals were educated in Denmark (Guðmundsdóttir 1965, Salvarsson 1995). However, ÍTM is clearly its own language, with its own patterns for word-order, vocabulary, syntactic differences from its parent Danish SL, etc. (Thorvaldsdóttir \& Brynjólfsdóttir 2016, Jónsson, Brynjólfsdóttir \& Sverrisdóttir 2015, i.a.). Currently, two ÍTM-based schools exist in the country, each of which is nestled within a monolingual Icelandic school: a preschool (leikskóli), for children 1-6y.o., and a so-called 'compulsory' (grunnskóli, for children 6-16 y.o.). Both of these schools are located in Reykjavik. A few other signing students live outside the capital but attend Icelandic-only based schools. ${ }^{1}$

According to Thorvaldsdóttir \& Stefánsdóttir (2015), Iceland is home to about 1800 adult Icelanders who sign ÍTM at various levels of proficiency (but whose proficiency has not been historically assessed). Among these individuals, approximately 17\% are deaf/hard of hearing, of whom $3 \%$ are use multilingual (ÍTM + another sign language, in addition to various written/spoken languages); the other $83 \%$ are hearing (Thorvalsdóttir \& Stefansdóttir 2015). What is apparent from these data is that the vast majority of the ÍTM signers are hearing (family,

\footnotetext{
${ }^{1}$ Notice that we intentionally focus here on the language rather deafness; the latter is discussed below.
} 
friends, and service providers to the DHH community); the next largest group are DHH adults born and raised in Iceland with Icelandic (typically the written version thereof as the second language). Finally, the smallest group of adult DHH ÍTM users in Iceland is comprised of the multilingual DHH individuals who have moved to Iceland in recent years and learned ÍTM as an additional language.

Traditionally, prior to the immigration of the DHH people to Iceland (i.e. the $3 \%$ above), DHH community had passed its language along differently than other SL communities: records show deaf children being born to (and raised in) only one family: in the 1800s (Guðmundsdóttir 1965, Salvarsson 1995, Sverrisdottir 2018). This means that the Icelandic DHH community has historically experienced something other than the typical process of passing the language along from a natural caregiver (e.g. a parent) to a child. Instead, DHH people have been learning ITM at school (which we know other DHH children also do, Henner et al. 2018, i.a.), via mobile learning tools (http://signwiki.org), and TV programs (https://is.signwiki.org/index.php/ Tinna_táknmálsálfur_2012-2013,_1._páttur), ${ }^{2}$ etc._-all from both deaf-of-hearing and hearing ÍTM users. Since the immigration of the foreign DHH to Iceland, this situation has changed: for the first time in the history of the community (not counting the aforementioned DHH family), the hereditary deafness has become a part of the community's profile: among the foreign-born DHH families, nine Deaf children are being raised (Sverrisdótttir 2018). In the home, these families report using Polish SL, Lithuanian SL, and American SL (respectively) to communicate with the children (see the discussion in Stefansdótttir et al. 2008 on the complications). In another family, Danish SL may be entering as well (according to the parental report). However, per (1), at school and during all the other daily activities outside of home, the children use ITM, as all the other DHH children of Iceland do. Moreover, given the sparsity of the numbers, $75 \%$ of Icelandic DHH children between ages 1-9 y.o. fall into this category - they are bona fide the first generation of the deaf-of-deaf children in Iceland, but they are also multilingual users of various SLs.

Finally, 100\% of Icelandic DHH children learn written, and sometimes spoken, Icelandic. Thus, at least one subgroup of those children - those with functionally restored access to sound (e.g. via a cochlear implant or a hearing aid) may be considered bimodal bilingual.

The picture we have painted here looks like this: while DHH children in Iceland receive a sign language early, it is an endangered language of the indigenous minority (Krausneker 2013, Stefansdótttir et al. 2019, Koulidobrova et al. 2020), and as such, it itself is in need of being documented (e.g. Haukson 2018, Sverrisdótttir 2018). But just as typically, the language is also affected by the synchronic inventions of the community, though perhaps more so than in other places, given the socio-linguistic profile of its users. It is therefore that much more crucial to track the development of this language itself (as the object of study) and its acquisition by its users, both as L1 and as another language. Here, we report the findings of a small part of a larger project, the aim of which is examination of acquisition of ÍTM more broadly and acquisition of ÍTM by DHH children specifically. We focus on acquisition of phonology.

3. Issues in acquisition of sign language phonology. Acquisition of sign language phonology involves an interplay of factors. We know, for instance, that native deaf signers, hearing L2

\footnotetext{
2 Note, however, that the show is not a part of an instructional package in any sense and was designed for entertainment purposes only (though its educational purpose should not be overlooked, as is the case with comparable programs in other languages in other countries, such as Sesame Street in the USA).
} 
learners, and hearing naïve signers are responsive to phonetic details of sign languages: HANDSHAPE, ORIENTATION, LOCATION, MOVEMENT (Hildebrandt \& Corina 2002, and many others). Being a theoretical primitive of sorts, such contrasts differentiate between different lexical items within different languages (such as ASL and ÍTM) and across them. For instance, as Figure 1 demonstrates, ASL 'mother' and 'father' contrast in LOCATION - the former is uttered on the jaw; the latter at temple/forehead. The HANDSHAPE (open hand), ORIENTATION (forward-facing palm), and MOVEMENT (bounce at the same location) are the same. In ÍTM, however, these signs contrast along a different 'parameter.' For instance, the signs for 'mother' and 'father' are articulated with the index-finger extended, with the rest of the hand facing the head of the signer, and both are dynamic signs involving two locations. However, 'mother' ends at the temple (Figure 2a) and 'father' starts at it (Figure 2b). That is, HANDSHAPE and ORIENTATION are the same and, depending on one's analysis, LOCATION and MOVEMENT are different.

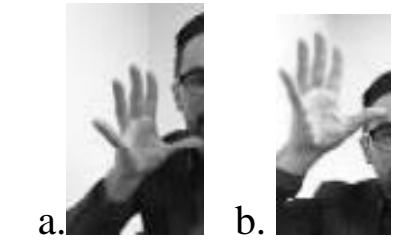

Figure 1. 'mother'/'father' (ASL)
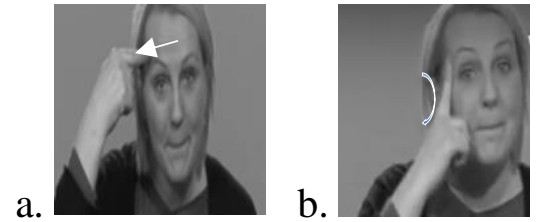

Figure 2. 'mother'/"father' (ÍTM)

But also, these contrasts offer minimal pairs between signs and non-signs. Figure 3 reproduces parts of a non-word repetition task for designed for Icelandic Sign Language (described below). The (nonce-)signs differ in HANDSHAPE.

a.

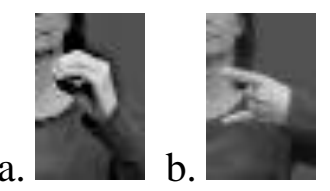

Figure 3. NWR (ÍTM), fragment

Thus, two things can be seen from Figures 1-3: a) unsurprisingly, one cannot assume that different sign languages have the same vocabulary, and, therefore, learners of multiple sign languages, just like learners of multiple spoken languages, have to learn new lexical items in addition to everything else they have to learn; $b$ ) a model of sign language phonology is required that accommodates such contrasts as well as the fact that they are not all treated on par by signers.

Brentari (1998, et seq.) has argued that some of these articulatory features may be more complex than others, simply because they encode more/different (types of) information: the status of these 'features' is not equal to one another (Figure 4). 


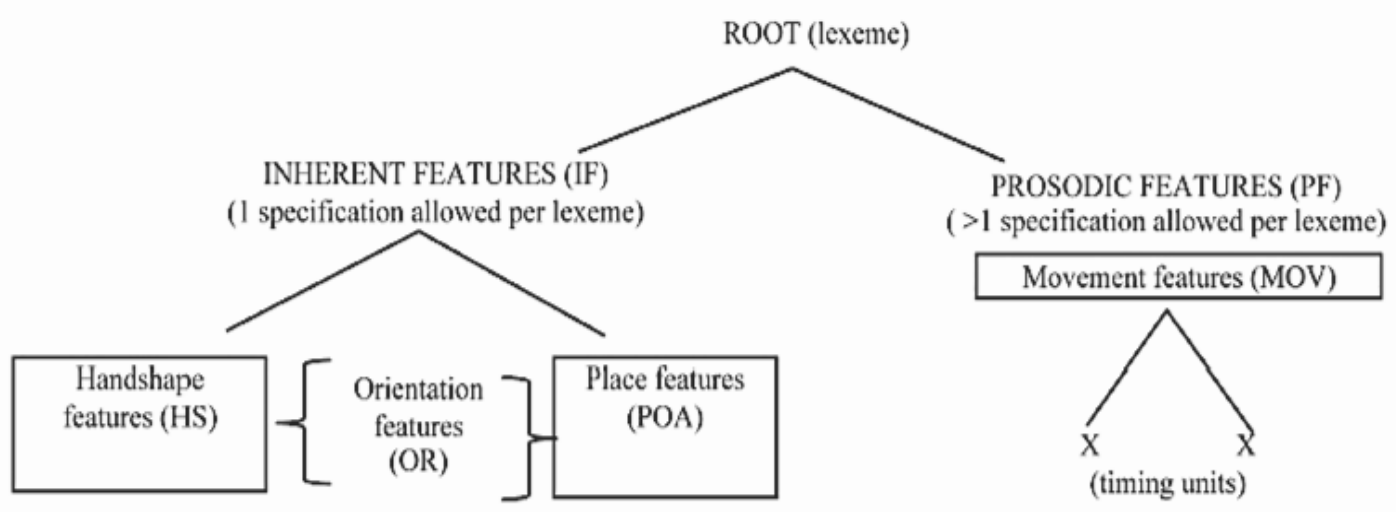

Figure 4. Prosodic Hierarchy Model (Brentari 1998)

In particular, HANDSHAPE has been shown to be special: it is difficult for late signing children (Singleton et al. 1993, i.a.) and non-signers/gesturers (Schembri 2005, Brentari 2006, et seq.); it also has been claimed to serve as a strong salient cue (Brentari 1993, Holt \& Lotto 2006, i.a.), including for signers of multiple sign languages (Koulidobrova et al. 2019, Luchkina et al. 2020, i.a.). Location tends to be easy for everyone (see Bochner et al. 2011 and references therein).

But what we also know is that that acquisition of phonology in general is a matter of development; scores on tasks probing phonological knowledge typically improve with age. This suggests that whatever assessment tool we choose to use here must account for the developmental trajectory, both in terms of linguistic and other growth-e.g. working memory, executive control, etc. For instance, some researchers have utilized a non-word repetition task as a measure of phonological knowledge (Vihman, 1995; Bernhardt \& Stemberger, 1998; a.o.). However, the ability to repeat a word involves also the ability to remember the word-i.e. a burden on working memory. This too is something children get better at as they get older (see Archibald 2018 for an overview). Thus, on their own, results of a non-word repetition task should be taken with some caution. One way to tell the difference between the working memory overload (and some other non-linguistic issues) and phonological development proper is to compare how the same participants perform on a non-word task and a real-word task, such as picture naming, for example. That is, if they make similar errors on a picture-naming task as they do on a non-word repetition task, this would confirm that the explanation for a particular behavior is likely to be linguistic (i.e. based on phonology). If, however, there is a clear difference between the types of errors/target responses between the two types of tasks, we may take that as evidence that at least one of the tasks probes something other than just phonology the explanation, or at least a part of it, may be non-linguistic in nature. This is precisely the path we pursue here.

4. Study. Seventeen Icelandic DHH children (ages 3-15 y.o.; mean age: 11;09) participated in the two experiments: a non-word repetition task and a picture-naming task, the goal of which was to observe the development of ITM phonology.

4.1. PARTICIPANTS. 35\% of the participants were deaf-of-deaf (and thus, bilingual in two sign languages, see section 2) and 65\% deaf-of-hearing; $14 \%$ were hard of hearing; $53 \%$ have cochlear implants; $40 \%$ have deaf signing siblings. Crucially, 100\% earned ÍTM before 36ms i.e. they are early learners (Mayberry \& Locke 2003, Mayberry 2008, Cormier et a. 2015, i.a.). $100 \%$ attend school in ÍTM, in addition to using the language for other activities. In other words, 
every individual in the participant pool is surrounded by ÍTM on a daily basis, perhaps in addition to some other languages.

4.2. Predictions. Three hypotheses $(\mathrm{H})$ underlie the study. First, we predicted that on a nonword repetition task, our participants would improve with age. Eventually, their performance would plateau (because they will have figured out the phonology of their language); moreover, at least for those who were exposed to the language early, this plateau would be at ceiling (or approaching it. Second, we predicted that, following the literature, the HANDSHAPE-targeting items will be necessarily more difficult and will result in more errors, at least during the initial stages of development. Further, if HANDSHAPE-tells informs about phonology (see section 4), we might expect the score on the HANDSHAPE-target items to predict the overall score on the NWR. Finally, if what we observe during NWR performance is due to phonological effects proper (and not some non-linguistic effects, such as working memory, executive function, etc.), then on a picture-naming task, the participants ought to behave similarly. The aforementioned predictions are articulated in (2)-(4) explicitly.

(2) H1 (a) The overall performance on NWR would track development;

(b) but would plateau and reach ceiling.

(3) $\mathbf{H} 2$ (a) Most errors will be in the HANDSHAPE.

(b) the score on the HANDSHAPE-target items will predict the total score on NWR.

(4) H3 Participants will perform similarly on a particular phonological feature across tests, with more errors in HANDSHAPE.

\section{Methodology}

5.1 EXPERIMENT 1: NON-WORD REPETITION TASK (NWR). A non-word repetition task targeting articulatory contrasts was administered to the entire participant pool. A subset of participants was administered the NWR twice (with an interval of 12-16 months). The task is an adaptation of (and therefore followed the guidelines and tested the constructs articulated in) Mann \& Marshall (2010), originally created for British Sign Language but since adapted for other languages as well. As in the BSL task, participants were required to repeat items contrasting along one of the articulatory dimensions. The task contains 40 items - all phonologically possible but nonexistent in ÍTM. Eight items were excluded from the final analysis due to being meaningful lexical items in the bilingual participants' other languages. The errors/successes were coded by one DHH- and one hearing raters. The data were coded by hearing coders in discussion with a DHH experimenter. Figure 5 shows sample items from the NWR.
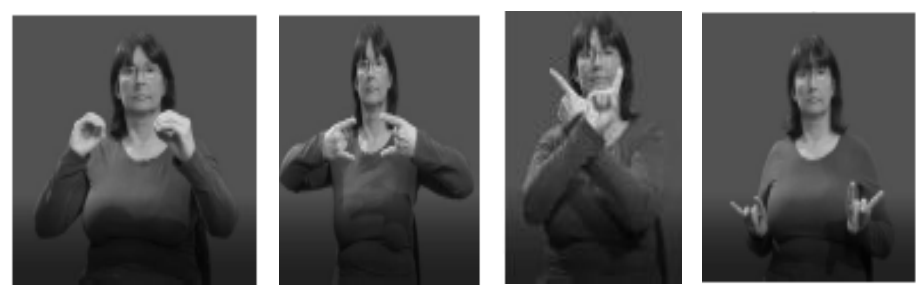

Figure 5. Sample items, NWR 
5.2 EXPERIMENT 2: PICTURE NAMING TASK. A picture naming task was conducted using a picture-set from the EVT-3 (Williams 2018). ${ }^{3}$ The EVT is a test of expressive English vocabulary, and thus, the complexity of representations in the pictures increases. Here, a subset of the EVT-3 stimuli was used - the first 40. The choice was made deliberately: the pictures were expected to elicit not only lexical items across various grammatical categories but also certain morpho-syntactic constructions outlining the relationship between various parts of the sentence. For instance, Figure 6a. elicits 'a cup,' while Figure 6b. may yield 'a rainbow,' 'a cloud,' 'there is a cloud to the right of the rainbow,' 'I see different colors: red, ...,' and so forth.

a.

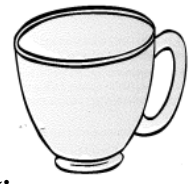

b.

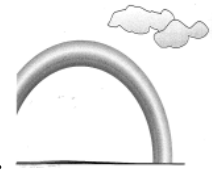

Figure 6. Sample, Picture-naming task (EVT-3, Williams 2018)

Using an easel with pictures, the experimenter (DHH adult), asked a DHH participant in ÍTM: "What do you see?", often followed up by "can you tell me more?" and "what else?" This methodology conforms with the established protocol for the EVT as well as other picture naming tasks. The participant sat across the desk from the experimenter; multiple cameras recorded both the child and the adult during the interaction. The data were transcribed and coded in ELAN by two DHH researchers; additional coding was done by hearing signing researchers. Following the methodology outlined in the original BSL-based specifications, the NWR results were coded for HANDSHAPE vs. MOVEMENT; the latter, in turn, was further analyzed as encoding a hand-internal change vs. path-movement (HIM vs. PM, respectively).

\section{Results}

6.1. RESULTS: NON-WORD REPETITION TASK (NWR). The overall results of the NWR task reveal an upward trajectory, both for the entire sample $\left(\mathrm{r}_{2}=0.86, \mathrm{p}<.000\right.$, Figure 7$)$ and for the subset of the participants who were tested twice, with a different result ( $\mathrm{t}=4.95, \mathrm{df}=5, \mathrm{p}=.002$; Figure 8). However, no ceiling effect was obtained. Nor age of acquisition effect was observed ( $>>.60)$.

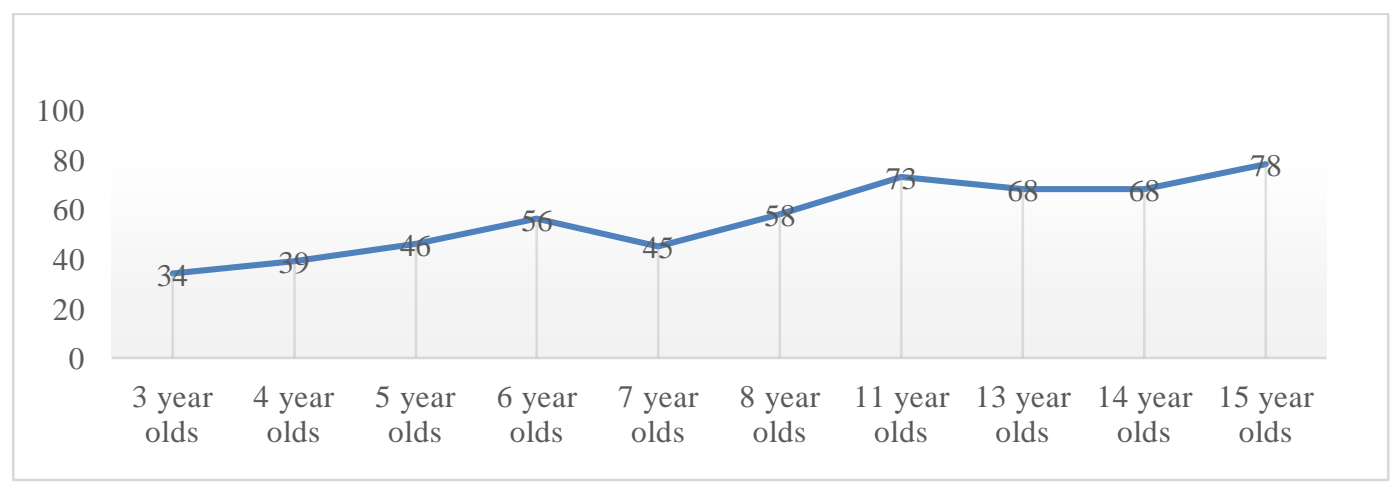

Figure 7. Scores; NWR (means)

3 Issues have been raised with respect to using the EVT with DHH populations (Costa et al. 2019). However, these concerns have chiefly to do with the fact that when the EVT is typically used with the DHH children, it is used as a measure of the spoken language (English). This is not what we have done. Instead, we have simply adopted a set of materials that have been pruned for cross-cultural biases (Williams et al. 2019). 


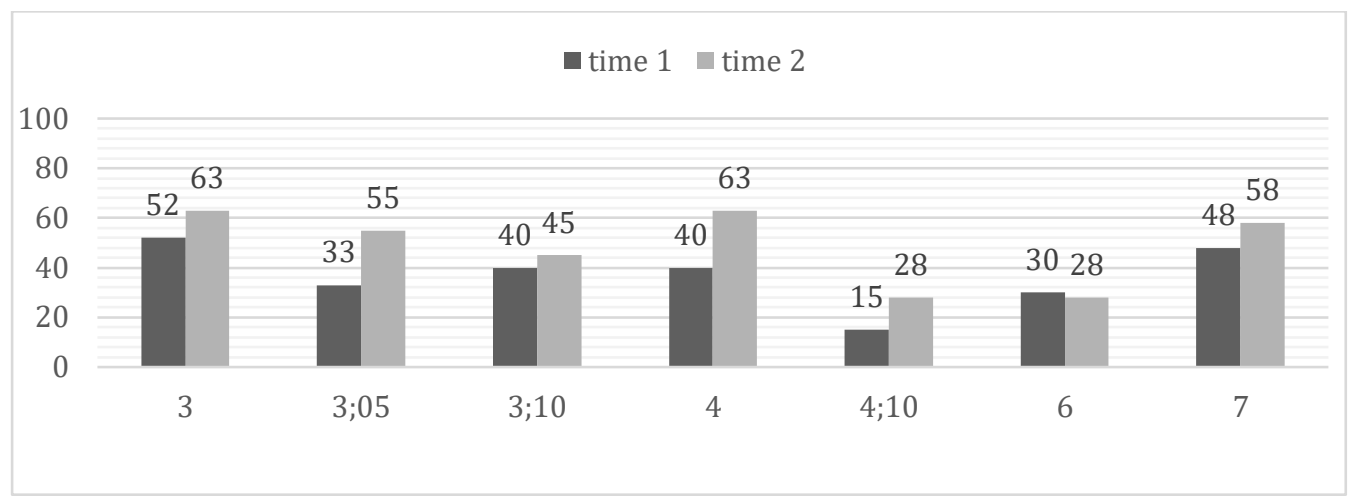

Figure 8. Scores for a subset of participants at time 1and time 2; NWR (means)

We further discovered that HANDSHAPE, MOVEMENT, and ORIENTATION were all separable, as revealed by paired samples tests in Table 1; the upward trajectory remained observable (linear $\mathrm{R}_{2}$ for each feature reported in Figure 13). Further, as has been observed for BSL, HANDSHAPE interacted with MOVEMENT (path (PM) and hand-internal (HIM)); multiple $\mathrm{R}_{2}=0.7466, p<.0001$; ANOVA: $\mathrm{F}(3,18.66), p<.0001$, see also Table 2).4

\begin{tabular}{|c|c|c|c|c|c|c|c|}
\hline & \multirow[b]{2}{*}{ Mean } & \multirow[b]{2}{*}{ SD } & \multicolumn{2}{|c|}{$\begin{array}{c}95 \% \text { confidence } \\
\text { interval }\end{array}$} & \multirow[b]{2}{*}{$\mathrm{t}$} & \multirow[b]{2}{*}{$\mathrm{df}$} & \multirow[b]{2}{*}{$p$ 2-tailec } \\
\hline & & & Lower & Upper & & & \\
\hline HANDSAPE-PM & 4.913 & 2.575 & 3.800 & 6.026 & 9.152 & 22 & $<.0001$ \\
\hline HIM[movement]-ORIENTATION & -5.043 & 6.011 & -7.643 & -2.44 & -4.024 & 22 & .001 \\
\hline HANDSAPE-HIM & 5.478 & 2.906 & 4.222 & 6.735 & 9.0042 & 22 & $<.0001$ \\
\hline ORIENTATION -PM & 4.478 & 5.607 & 2.053 & 6.903 & 3.830 & 22 & .001 \\
\hline
\end{tabular}

Table 1. NWR scores. Paired sampled t-tests of items targeting particular articulatory feature.

\begin{tabular}{lll} 
& $\mathrm{R}$ & $p$ \\
\hline HANDSHAPE - PM & .884 & $<.0001$ \\
PM-HM & .785 & $<.0001$ \\
HANDSHAPE - HIM & .852 & $<.0001$ \\
\hline
\end{tabular}

Table 2. NWR scores. Paired Samples; Correlations; $N=23$

A variety of types of errors were observed, among which we find HANSHAPE errors (as in Figure 9b), ORIENTATION errors (as in Figure 10b) $)^{5}$ and both (as in Figure 11b).

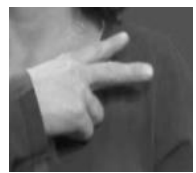

a. Target

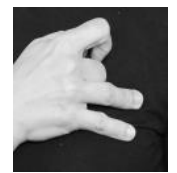

b. Response

Figure 9. NWR, HANDSHAPE error

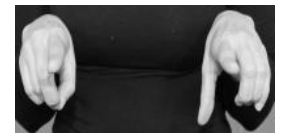

a. Target

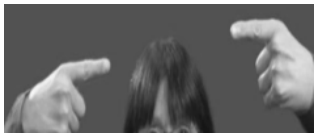

b. Response

Figure 10. NWR, ORIENTATION error

\footnotetext{
${ }^{4}$ Various combinations were tested; only statistically significant pairs are shown here for the sake for space.

${ }^{5}$ Note, Fig $10 \mathrm{~b}$ is also LOCATION error. A question arises whether all ORIENTATON errors are ORIENTATION+. We are currently analyzing the data in order to answer this question. Consider GREEN and SOFA in Figure 15: here too the hands move to a different location in space.
} 


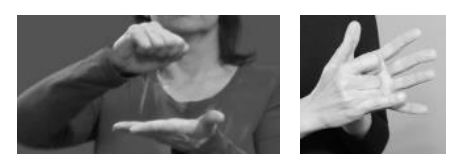

a. Target b. Response

Figure 11. NWR, HANDSHAPE + ORIENTATION error

The upward trajectory was observed for each of the articulatory features (see Figure 12) with no effect of any one of them on the total performance. Contrary to prediction, HANDSHAPEtargeting items received the highest scores. Nor did score on the HANDSHAPE targets predict the overall score on the task: $\mathrm{r} 2=0.068, p=.248$. Participants were least successful on MOVEMENT targets, followed by ORIENTATION targets. The former is not entirely surprising: at least in ASL, MOVEMENT contrasts tend to be difficult for all types of signers - hearing L2, Deaf L1 as well as silent gesturers (cf. Williams \& Newman 2016). However, the latter is less expected: literature does not report find ORIENTATON difficulties (except Rosen 2004 for L2 learners). Finally, the fact that the HANDSHAPE appears to be the most error-free is also surprising.

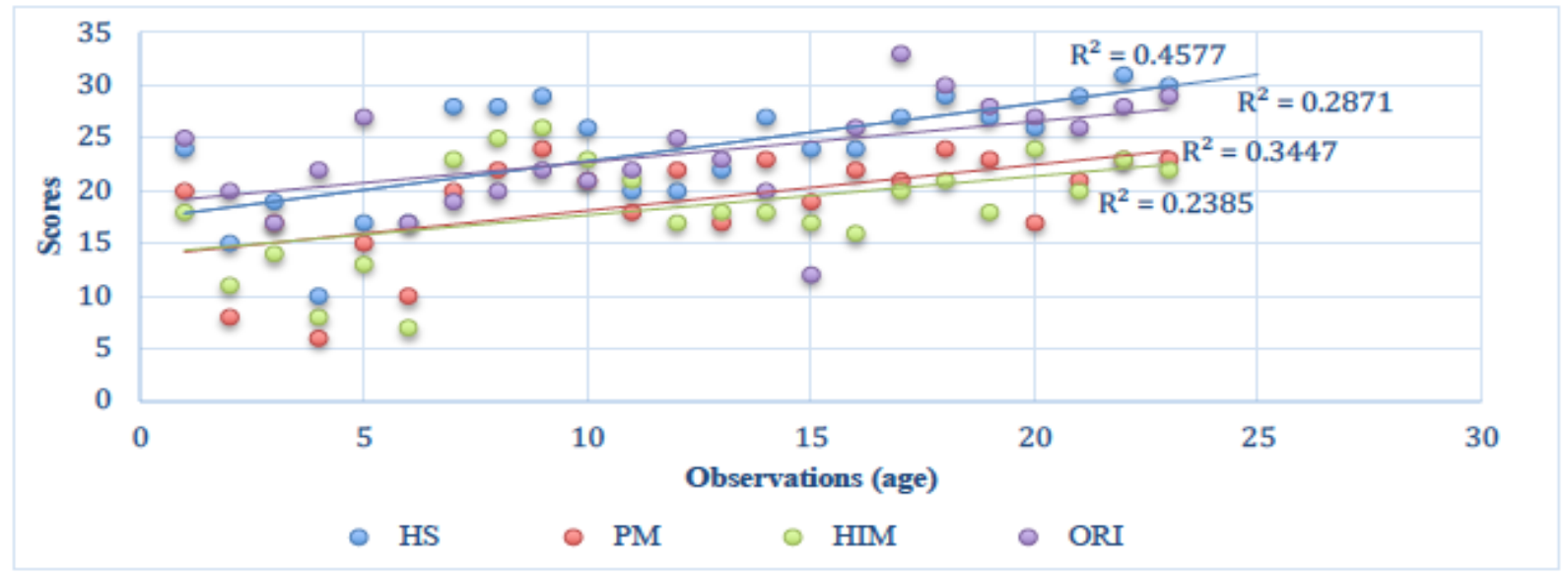

Figure 12. NWR. Item analysis. Scores targeting different articulatory features.

6.2. Results: Picture NAming TASK. The data from the Picture Naming Task are still under analysis; however, preliminary results reveal that out of the 40 lexical items we were hoping to elicit, consistently produced by the majority of children in the sample were the items in Table 3.

\begin{tabular}{lll} 
Nouns & Verbs & Adjectives \\
\hline CUP, CAR, DOG, SPOON, APPLE, & EAT, SLEEP, & RED, BLUE, \\
BALL, COOKIE, FAMILY, STAR, & RUN & GREEN, \\
DUCK, ELEPHANT, BOAT, & & YELLOW, \\
PENCIL, CLOCK, CAKE, & & GRAY, \\
RABBIT, CHILD, BED, SOFA, & & BROWN \\
UMBRELLA, LEAF, KEY &
\end{tabular}

Table 3. Picture Naming Task. Common items/grammatical categories across participants.

$100 \%$ of participants used non-target forms (2-14\%) across the entire sample. Item analysis shows that the lexical items in (5a) were typically produced in a target-like manner $(88 \%)$. 
Conversely, the items in (5b) were judged 'non-adult'/'wrong' by DHH researchers $65 \%$ of cases. Finally, with a subset of lexical items (5c), participants supplied unexpected forms:

\section{(5) a. BOOK, CAR, KEY, HOUSE, DOG, SPOON, APPLE, RUN, ELEPHANT \\ a. FAMILY, SOFA, CLOCK, AIRPLANE \\ b. SOFA (59\%), FAMILY (65\%), CUP (47\%), CLOCK (47\%)}

Various types of lexical variations were observed, including HANDSHAPE, as in Figure 13b. However, $75 \%$ of non-target behaviors were judged to be errors of ORIENTATION (as in Figure $14 \mathrm{c}-\mathrm{d})$. The difference between the rates of HANDSHAPE vs. ORIENTATION errors was significant: $\mathrm{t}=2.69, \mathrm{df}=9, p .0123 ; \mathrm{t}=0.72, p<.0001$. A number of analyses are being conducted.

a. Target. DRINK/CUP
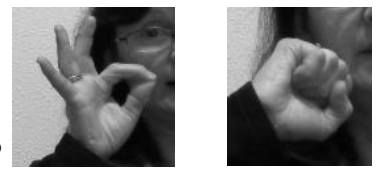

b. (A copy of) The child's production Figure 13. Picture Naming Task. HANDSHAPE error. ${ }^{6}$

a. Target. GREEN
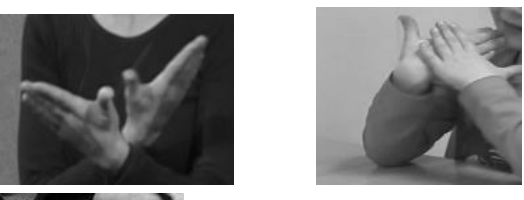

b. The child's production

c. Target. SOFA
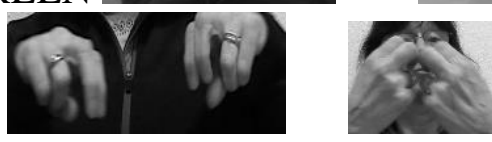

d. (A copy of) The child's production

Figure 14. Picture Naming Task. ORIENTATION error.

7. Discussion. Based on the previous research, we made a number of predictions (in (2)-(4)). In (2a), we had predicted that the overall performance on the non-word repetition task would track development, as it has done for other languages. And indeed, we saw a steady increase in scores for all participants, with a clear upward trajectory across articulatory features (when analyzed componentally) and in total scores for the susbset of the participants tested multiple times. However, in (2b), we also predicted that this trajectory would plateau - i.e. learning of phonology does not ordinarily continue until one's teens. Yet, this is precisely what we observed here. In an event of such a result, we had expected to find a contribution of early language input or daily ÍTM practice but we did not find that such an effect. Thus, while the first part of our $\mathbf{H 1}$ was supported, the second one was not.

${ }^{6}$ An alternative form of the CUP is shown in Figure i. below.

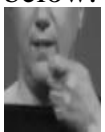

Figure i. BOLLI 'cup' (https://is.signwiki.org/index.php/Bolli)

If this is the child's target form (a.k.a. the HANDSHAPE is not F- as in Fig. 14a. but X-in Fig.i), then the change here is still from a marked handshape to an unmarked one. Here, however, the ORIENTATION is quite different: if the target form is Fig.i, rather than Fig.13a, then the wrist is expected to be rotated towards the signer rather than towards the interlocutor (as it is in Fig. 13b). Either way then, Fig. 14b should be treated as a non-adult version of ÍTM — containing either a HANDSHAPE- or an (HANDSHAPE +) ORIENTATION error. 
In (3), guided by the literature, we had predicted that the score on the items targeting HANDSHAPE would predict the overall score on the non-word repetition task - i.e. one way to assess development of phonology is to assess how children are replicating HANDSHAPE (shown to be notoriously difficult). We saw instead is that while scores targeting various articulatory features are distinct (including ORIENTATION), success on items targeting HANDSHAPE did not predict success on the overall score, though success on HANDSHAPE predicted success on MOVEMENT items. Crucially, while all participants made errors in HANDSHAPE, it was not the most non-target feature in their production, both in real- and non-words. In other words, our $\mathbf{H} 2$ was not supported.

Finally, we expected that our participants would make similar types of errors across the two tasks; this error we predicted to be HANDSHAPE (see above). The results of the two studies (albeit still preliminary) suggest that while the latter part of the $\mathbf{H 3}$ was not borne out, the former part was. Figure 15 demonstrates that among the participants ( $x$-axis) that have produced HANDSHAPE and ORIENTATION errors across different tasks (59\%), the rates of ORIENTATION errors surpass the rates of HANDSHAPE-type error.

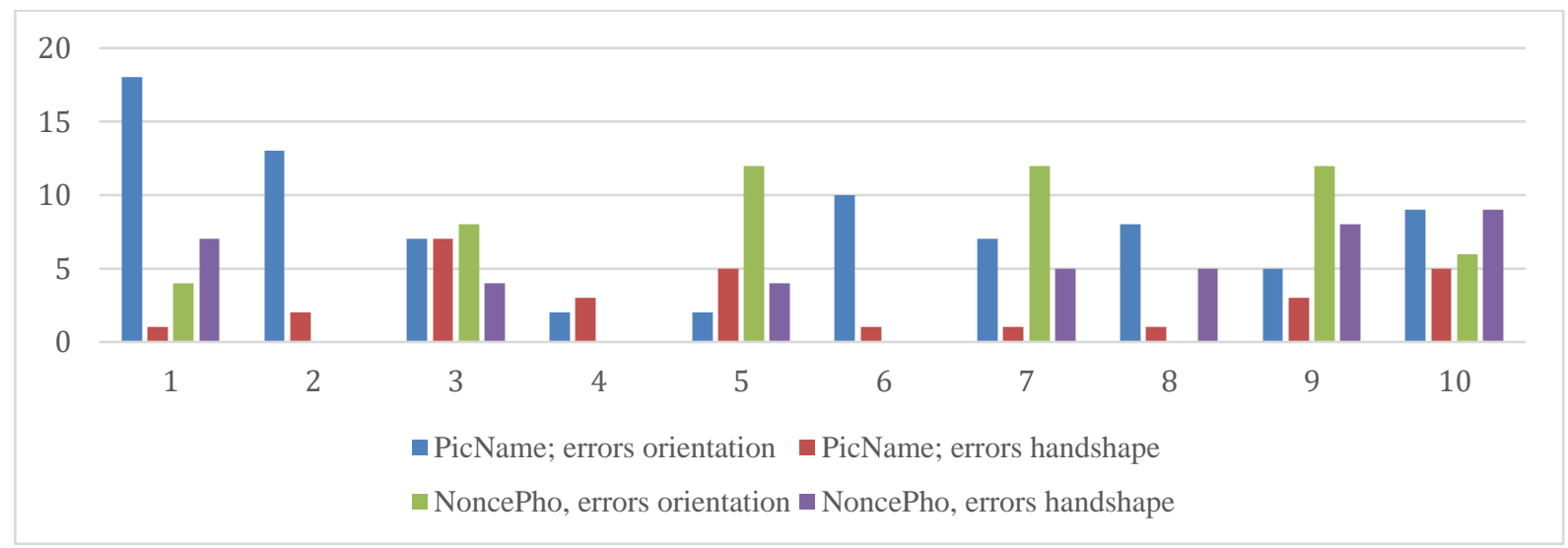

Figure 15. Error types across tasks (HANDSHAPE vs. ORIENTATION)

What do we make of these data?

One possible conclusion one might draw from the studies reported here is that the NWR does not work as the test of ÍTM phonology - after all, NWR is not an assessment tool but, rather, a language plus working memory task (even if though we might have expected young adults to do well on it). Additionally, given that (1) we see the lack of ceiling effect, even with 15 year olds, despite the fact that they are early learners of the language, and (2) the well-documented HANDSHAPE-effect does not appear to be borne out, we might conclude that the NWR does not probe what we might have expected it to probe. Here, the results of both the NWR and Picture Naming Task remain under analysis, being and followed up with semi-naturalistic samples.

It is, however, possible that the explanation lies elsewhere. Another probable reason for the lack of the ceiling effect in the NWR is the fact that every participant in the pool is a heritage language user (Polinsky \& Scontras 2016, i.a.). To elaborate: while every single child attends school where the instructional methodology involves ÍTM (educational content is either delivered in ÍTM directly or interpreted into it), the language still has the status of a minority language in the school setting and is not actively taught; moreover, many learners go home to households that are linguistically not enriching. This immediately suggests that the learners may be expected to behave as other heritage language users do. As by now many studies show, such 
individuals tend to present morpho-phonological patterns different from L1 monolinguals (see an overview in Lohndal et al. 2019).

Last, but certainly not least, consider the task of a (young) signer on an imitation task, especially one that is unpredictable with respect to frequency distributions, such as a non-word repetition task. Such language users/learners must rely on at least four imitation strategies (in (6)) available to learners in comprehending complex spatial configurations but also for acquiring the phonological form of individual lexical signs.

(6) 1. Anatomical strategy: Activate the same muscles as the model, regardless of the hand dominance of the signer.

2. Mirroring strategy: Produce a mirror image of what the signer does.

3. Visual matching strategy: Reproduce the sign as it appears from the learner's perspective.

4. Reversing strategy: Perform a mental spatial transformation on the observed sign and reproduce what the signer does after checking for differences in hand dominance.

(Shield \& Meier 2018)

Arguably, all such strategies are something children have to learn and, thus, are expected to continue improving with age. Moreover, Shield and Meir (2018) find that only the reversing strategy (with mental spatial transformation, (6.4)) yields the correct form in all cases, while other types have been shown to result in errors across various types of populations, with L2 learners having relying on mirroring (as in (6.2)) and autistic learners on visual matching (as in (6.3)).

What the aforementioned suggests is that what we have lumped here under ORIENTATION errors may be better analyzed as more fine-grained along these lines - i.e. something to do with acquisition of the gestural system, mirroring it, and representing what one sees/knows by using this set of tools vis-à-vis the phonological system of a particular language; for instance, something can be a mirroring/mental-rotation/perspective-taking error vs. an actual phonological one. And, in fact, among the ORIENTATION errors we observed during the NWR, there were cases like Figure 16b, which may be better analyzed as a non-target from the point of view of (6) instead.

a. Target
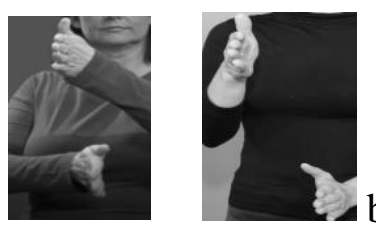

b. A copy of the child's production.

Figure 16. NWR; a sample item with a response.

We know that a focused spatial array manipulation task targeting (6.2), for instance, flushes out atypicalities (Shield 2011, et seq.), and on such tasks, native signers outperform non-native signers (Emmorey et al. 1998, Martin \& Seda 2006, i.a.). But what this also suggests is that here, we might expect additional effects. For instance, we know that irrespective of sign language skills, on such spatial rotation tasks, (non-signing) bilinguals outperform monolinguals (Greenberg et al. 2013, i.a.). One question is whether we will observe a bilingualism effect here - recall, a number of participants are bilingual, and they are quite likely the most fluent users of the language because they are the one group that receive sign language input at home. We might expect this subset of the participants to outperform the rest of the signers here. Incidentally, the 
significance of ORIENTATION has also been observed in L2 deaf learners of ASL who view it as a perceptual cue (Rosen 2004, Koulidobrova et al. 2019, Luchkina et al. 2020). That is, precisely because mental rotation/mirroring tasks may be something that signing bilinguals with typical language skills are predicted to be better at than monolinguals, we might expect their ORIENTATION scores to be higher than the ORIENTATION scores for other type of signers. But then, despite what we have done throughout, we must carefully disassociate ORIENTATION errors from 'mirroring'/ 'mental rotation' - something that a mental rotation task, in addition to a phonological one, should accomplish.

It is also possible that the explanation for the facts presented here lies in the difference between ÍTM and ASL. That is, ASL learners find HANDSHAPE difficult but ÍTM learners do not. Such an approach would not in principle be odd: which articulatory featural bundles languages privilege for which reason has been part and parcel of phonological theorizing for the past 60 or so years. However, given the model of sign phonology in Figure 4, such an explanation would require a change in the theory of sign phonology. For in the current model, the reason behind difficulty of HANDSHAPE is its inherent complexity (of joints, etc.); in this, HANDSHAPE differs starkly from LOCATION and ORIENTATION, with the former being a 'secondary' feature all together. The data presented here suggest a revision to such a model, since ITM signing children make orientation/mirror rotation errors - ORIENTATION is relevant after all and we should be looking at it. Following the same line of reasoning, and especially given the absence of the literature on some of the participants' home languages, we should consider examining other bilingual populations (e.g. bimodal bilinguals - e.g. hearing children of deaf adults) for comparison.

One more thing must be taken into consideration. It is of course possible that different sign languages utilize space differently; specifically, it is possible that they orient their discourse differently in space. Thus, given that a number of the children in the sample are bilingual in the languages with no accessible literature, there is at least in principle a possibility that the 'mental rotation' effects come from the child's other language, and we simply are do not know this. We are currently analyzing the data for the language contribution (given the apparent influences of certain members of this linguistic community on the synchronic state of child ITM). In a set of analyses, we ask whether the results we observe as contributed by the children's multilingualism vis-à-vis native signing. A number of other questions remain, which we leave for future research.

8. Conclusion. In this paper, we reported the results of two experiments the goal of which was to examine the patterns of emerging phonology in Icelandic Sign Language (ÍTM). Both tasks were administered to 17 ÍTM signers, $100 \%$ of whom began their acquisition of ÍTM early and, thus, were expected to excel at the tasks by a particular age. In the first experiment, participants were required to imitate nonce signs that were compatible with ITM phonology albeit not being a part of the ÍTM lexical repertoire. The participants demonstrated an upward trajectory, suggesting that the task does in fact probe the increasing proficiency in ÍTM. In the second experiment - a picture naming task, - the participants were expected to produce various lexical items. This task targeted the same phonological contrasts as the non-word repetition task: HANDSHAPE, ORIENTATION, LOCATION, and MOVEMENT. We reasoned that if the phonological development (visà-vis working memory, executive control, etc.) were responsible for certain errors, then the type of error would be expected across tasks. This is precisely what we obtained.

Contrary to the literature, however, the highest numbers of errors the children made were not errors associated with HANDSHAPE. Instead, in both tasks, we observed a prevalence of errors of orientation. Previous research has suggested that ORIENTATION may be responsible for some 
acquisition effects, dissociable from the effects of HANDSHAPE: while ultimately, HANDSHAPE may be about 'complexity,' ORIENTATION may be about something else altogether - mirroring, perspective taking, and other articulatory effects, associated with sign mapping and production.

\section{References}

Allen, Timothy \& Charlotte Enns. 2013. A psychometric study of the ASL Receptive Skills Test when administered to deaf 3-, 4-, and 5-year-old children. Sign Language Studies 14(1). $58-79$.

Act No 61/2011 Respecting the Status of the Icelandic Language and Icelandic Sign Language. https://www.government.is/media/menntamalaraduneytimedia/media/frettir2015/Thyding-log-um-stodu-islenskrar-tungu-og-islensks-taknmalsdesember-2015.pdf (accessed 3 August 2018).

Archibald, Lisa. 2018. The reciprocal influences of working memory and linguistic knowledge on language performance: Considerations for the assessment of children with developmental language disorder. Language Speech and Hearing Services in Schools 49(2). 424. https://doi.org/10.1044/2018_1shss-17-0094.

Bochner Joseph, Karen Christie, Peter Hauser \& James Searls. 2011. When is a difference really different? Learners' discrimination of linguistic contrasts in American Sign Language. Language Learning 61. 1302-1327.

Brentari, Diane. 1998. A prosodic model of sign language phonology. Cambridge, MA: MIT Press.

Brentari, Diane, Marie Coppola, Ashley Jung \& Susan Goldin-Meadow. 2013. Acquiring word class distinctions in American Sign Language: Evidence from handshape. Language Learning and Development. https://doi.org/10.1080/15475441.2012.679540.

De Meulder, Maartje, Joseph J. Murray \& Rachel Mckee. 2019. The legal recognition of Sign Languages: Advocacy and outcomes around the world. Bristol, UK: Multilingual Matters.

Dollaghan, Chris \& Thomas Campbell. 1998. Nonword repetition and child language impairment. Journal of Speech, Language and Hearing Research 1. https://doi.org/10.1044/jslhr.4105.1136.

Emmorey, Karen, Edward Klima, and Hickok, George. 1998. Mental rotation within linguistic and non-linguistic domains in users of American Sign Language. Cognition 68(3). 221-46.

Enns, Charlotte \& Rosalind Herman. 2011. Adapting the Assessing British Sign Language Development: Receptive Skills Test into American Sign Language. Journal of Deaf Studies and Deaf Education 16(3). 362-374.

Gathercole Susan. 2006, Complexities and constraints in nonword repetition and word learning. Applied Psycholinguistics 27(4). 599-613.

Guðmundsdóttir, Bryndís. 1989. Heyrnarlausir á Íslandi: sögulegt yfirlit. Reykjavík: Félag heyrnarlausra.

Hauksson, Haukur Darri. 2018. Icelandic Deaf culture: A discourse analysis. Reykjavik: University of Iceland MA dissertation.

Hildebrandt, Ursula \& David Corina. 2002. Phonological similarity in American Sign Language. Language and Cognitive Processes 17(6). 593-612.

Holt, Lori \& Andrew Lotto. 2006. Cue weighting in auditory categorization: Implications for first and second language acquisition. Journal of the Acoustical Society of America 119(5). https://doi.org/10.1121/1.2188377. 
Koulidobrova, Elena, Rannveig Sverrisdóttir \& Valgerður Stefánsdóttir. 2020. Putting the money where the mouth is: Icelandic Sign Language and the UNDRIP. Manuscript. Central Connecticut State University.

Koulidobrova, Elena. 2019. Argument omission in SignL2 acquisition by deaf learners: Back to the inhibition. In Tania Ionin \& Matthew Rispoli (eds.), Three streams of generative language acquisition research. 297-318. Amsterdam: John Benjamins. https://doi.org/10.1075/lald.63.15kou.

Krausneker, Verena. 2015. Ideologies and attitudes toward Sign Languages: An approximation. Sign Language Studies 15. 411-431.

Luchkina, Tatiana, Elena Koulidobrova \& Jeffrey Palmer. 2020. When you CAN see the difference: The phonetic basis of sonority in American Sign Language. Proceedings of the 2019 Annual Meeting on Phonology. In press. https://oi.org/10.3765/amp.

Martin, Amber \& M.D. Sera. 2006. Acquisition of spatial constructions by users of American Sign Language and English. Journal of Deaf Studies and Deaf Education.11. 391-402.

Mann, Wolfgang \& Chloë R. Marshall. 2010. Building an Assessment Use Argument for sign language: the BSL Nonsense Sign Repetition Test. International Journal of Bilingual Education and Bilingualism 13(2). 243-258. https://doi.org/10.1080/13670050903474127.

Mann, Wolfgang \&Tobias Haug. 2014. Mapping out guidelines for the development and use of sign language assessments: Some critical issues, comments and suggestions. In David Quinto-Pozos (ed.), Multilingual aspects of Signed Language communication and disorder. 123-142. Bristol: Multilingual Matters.

Lohndal, Terje, Jason Rothman, Tanja Kupisch \& Marit Westergaard 2019. Heritage language acquisition: What it reveals and why it is important for formal linguistic theories. Language and Linguistic Compass 13:e12357. https://doi.org/10.1111/lnc3.12357 .

Polinsky, Maria, \& Georgi Scontras. 2020. Understanding heritage languages. Bilingualism: Language and Cognition 23(1). 4-20. https://doi.org///10.1017/S1366728919000245.

Reagan, Timothy. 2019. Linguistic legitimacy and social justice. New York: Palgrave Mcmillan.

Rosen, Rusty. 2004. Beginning L2 production errors in ASL lexical phonology: A cognitive pho nology model. Sign Language Linguistics 7. 31-61. https://doi.org/10.1075/s11.7.1.04beg.

Salvarsson, Gunnar.1995. Daufir duga: saga og samfélag heyrnarlausra. Reykjavík: Námsgagnastofnun.

Shield Aaron \& Richard Meier. 2018. Learning an embodied visual language: Four imitation strategies available to sign learners. Frontiers in Psychology 9. 811. https://doi.org/10.3389/fpsyg.2018.00811 .

Schembri, Adam, Caroline Jones \& Denis Burnham. 2005. Comparing action gestures and classifier verbs of motion: Evidence from Australian Sign Language, Taiwan Sign Language, and nonsigners' gestures without speech. The journal of Deaf Studies and Deaf Education 10(3). 272-290. https://doi.org/10.1093/deafed/eni029.

Skutnabb-Kangas, Tove \& Robert Dunbar. 2010. Indigenous children's education as linguistic genocide and a crime against humanity? A global view. Gáldu Čála. Journal of Indigenous Peoples' Rights 1.

Porvaldsson, Reynir Berg. 2010. Saga heyrnarlausra á Íslandi. Reykjavík: Félag heyrnarlausra Thorvaldsdóttir, Kristin \& Elisa Brynjólfsdóttir. 2016. Sign language: Scandinavia. In G. Gertz \& P. Boudreault (eds.), The SAGE Deaf Studies encyclopedia. 812-813. Thousand Oaks, CA: SAGE Publications. https://doi.org/10.4135/9781483346489.n259. 
Thorvaldsdóttir, Kristín \& Stefánsdóttir, Valgerður. 2015. Icelandic Sign Language. In J. Bakken Jepsen, G. De Clerck, S. Lutalo Kiingi \& W.B. McGregor (eds.), Sign Languages of the world. 409-429. Berlin/Boston: De Gruyter Mouton \& Ishara Press.

Vihman, Marylin. 1995. Phonological development: The origins of language in the child. Oxford: Blackwell.

Stefánsdóttir, Valgerður, Ari Páll Kristinsson \& Júlía Hreinsdóttir. 2019. Did the legal recognition of Icelandic Sign Language meet the expectations of Deaf people? In De Meulder, Maartje, Joseph J. Murray \& Rachel Mckee (eds.), The legal recognition of Sign Languages: Advocacy and outcomes around the world. Bristol, UK: Multilingual Matters.

Sverrisdóttir, Rannveig. 2018. Is the Icelandic Sign Language an endangered language? In S. Drude, N. Ostler \& M. Moser (eds.), Endangered languages and the land: Mapping landscapes of multilingualism, Proceedings of FEL XXII/2018 in Reykjavík. 113114. http://www.elpublishing.org/PID/4017.

Williams, Kathleen. 2018. Expressive Vocabulary Test, 3rd ed. (EVT-3). Toronto, Canada: Pearson. 